\title{
Tirabrutinib Hydrochloride
}

National Cancer Institute

\section{Source}

National Cancer Institute. Tirabrutinib Hydrochloride. NCI Thesaurus. Code C141426.

The hydrochloride salt form of tirabrutinib, an orally available formulation containing an inhibitor of Bruton agammaglobulinemia tyrosine kinase (BTK), with potential antineoplastic activity. Upon administration, tirabrutinib covalently binds to BT K within B cells, thereby preventing B cell receptor signaling and impeding B cell development. As a result, this agent may inhibit the proliferation of B cell malignancies. BTK, a cytoplasmic tyrosine kinase and member of the Tec family of kinases, plays an important role in $B$ lymphocyte development, activation, signaling, proliferation and survival. 